\title{
Influence of freshwater input on the skill of decadal forecast of sea ice in the Southern Ocean
}

\author{
V. Zunz ${ }^{1, *}$ and H. Goosse ${ }^{1}$ \\ ${ }^{1}$ Université catholique de Louvain, Earth and Life Institute, Georges Lemaître Centre for Earth and Climate Research, \\ Louvain-la-Neuve, Belgium \\ * Invited contribution by V. Zunz, recipient of the EGU Young Scientists Outstanding Poster Paper Award 2013.
}

Correspondence to: V. Zunz (violette.zunz@uclouvain.be)

Received: 8 May 2014 - Published in The Cryosphere Discuss.: 9 July 2014

Revised: 11 February 2015 - Accepted: 2 March 2015 - Published: 17 March 2015

\begin{abstract}
Recent studies have investigated the potential link between the freshwater input derived from the melting of the Antarctic ice sheet and the observed recent increase in sea ice extent in the Southern Ocean. In this study, we assess the impact of an additional freshwater flux on the trend in sea ice extent and concentration in simulations with data assimilation, spanning the period 1850-2009, as well as in retrospective forecasts (hindcasts) initialised in 1980. In the simulations with data assimilation, the inclusion of an additional freshwater flux that follows an autoregressive process improves the reconstruction of the trend in ice extent and concentration between 1980 and 2009. This is linked to a better efficiency of the data assimilation procedure but can also be due to a better representation of the freshwater cycle in the Southern Ocean. The results of the hindcast simulations show that an adequate initial state, reconstructed thanks to the data assimilation procedure including an additional freshwater flux, can lead to an increase in the sea ice extent spanning several decades that is in agreement with satellite observations. In our hindcast simulations, an increase in sea ice extent is obtained even in the absence of any major change in the freshwater input over the last decades. Therefore, while the additional freshwater flux appears to play a key role in the reconstruction of the evolution of the sea ice in the simulation with data assimilation, it does not seem to be required in the hindcast simulations. The present work thus provides encouraging results for sea ice predictions in the Southern Ocean, as in our simulation the positive trend in ice extent over the last 30 years is largely determined by the state of the system in the late 1970s.
\end{abstract}

\section{Introduction}

The sea ice extent in the Southern Ocean has been increasing at a rate estimated to be between 0.13 and 0.2 million $\mathrm{km}^{2}$ per decade between November 1978 and December 2012 (Vaughan et al., 2013). The recent work of Eisenman et al. (2014) suggests that the positive trend in Antarctic sea ice extent may be in reality smaller than the value given in Vaughan et al. (2013). Indeed, an approximate continuation of the trends in sea ice extent corresponding to the version 1 of the Bootstrap algorithm provides a value around 0.1 million $\mathrm{km}^{2}$ per decade between November 1978 and December 2012 (Fig. 1b of Eisenman et al., 2014). Nevertheless, even a slight expansion of the Antarctic sea ice is in clear contrast with the behaviour of its Arctic counterpart which is currently shrinking (e.g. Turner and Overland, 2009).

The processes that drive the evolution of the Antarctic sea ice and the causes of its recent expansion are still debated. The hypothesis that the stratospheric ozone depletion (Solomon, 1999) could have been responsible for the increase in sea ice extent is not compatible with the results of some recent model analyses (e.g. Sigmond and Fyfe, 2010, 2013; Bitz and Polvani, 2012; Smith et al., 2012) but the impact of ozone changes involves complex mechanisms that need to be further investigated (Ferreira et al., 2015). Besides, other studies have underlined the fact that the positive trend in sea ice extent could be attributed to the internal variability of the system (e.g. Mahlstein et al., 2013; Zunz et al., 2013; Polvani and Smith, 2013; Swart and Fyfe, 2013). Nevertheless, this explanation cannot be confirmed by present-day general circulation models (GCMs) involved in the Fifth Coupled Model Intercomparison Project (CMIP5, 
Taylor et al., 2011). Indeed, because of the biases present in those models, they often simulate a seasonal cycle or an internal variability (or both) of the Southern Ocean sea ice that disagrees with what is observed (e.g. Turner et al., 2013; Zunz et al., 2013).

Hypotheses related to changes in the atmospheric circulation or in the ocean stratification (e.g. Bitz et al., 2006; Zhang, 2007; Lefebvre and Goosse, 2008; Stammerjohn et al., 2008; Goosse et al., 2009; Kirkman and Bitz, 2010; Landrum et al., 2012; Holland and Kwok, 2012; Goosse and Zunz, 2014; de Lavergne et al., 2014) have also been proposed. In particular, a link between the melting of the Antarctic ice sheet, especially the ice shelves, and the formation of sea ice has been recently proposed (e.g. Hellmer, 2004; Swingedouw et al., 2008; Bintanja et al., 2013). The meltwater input from the ice sheet leads to a fresher and colder surface layer in the ocean surrounding Antarctica. As a consequence, the ocean gets more stratified and there is less interaction between the surface and the warmer and saltier interior ocean, leading to an enhanced cooling of the surface. This negative feedback could counteract the greenhouse warming and could thus contribute to the expansion of the sea ice. Estimates of the Antarctic ice sheet mass imbalance are available thanks to satellite observations and climate modelling. These estimates report an increase in the melting of the Antarctic ice sheet over the past decade, mainly coming from West Antarctica (e.g. Rignot et al., 2008; Velicogna, 2009; Pritchard et al., 2012; Shepherd et al., 2012). According to Bintanja et al. (2013), incorporating realistic changes in the Antarctic ice sheet mass in a coupled climate model could lead to a better simulation of the evolution of the sea ice in the Southern Ocean. For past periods, this may be achieved using estimates of changes in mass balance but for future projections this requires a comprehensive representation of the polar ice sheets in models. Besides, Swart and Fyfe (2013) have shown that the freshwater derived from the ice sheet is unlikely to affect significantly the recent trend in sea ice extent simulated by CMIP5 models, when imposing a flux whose magnitude is constrained by the observations.

In addition to the studies devoted to a better understanding of the causes of the recent variations, models are also employed to perform projections for the changes at the end of the 21 st century and predictions for the next months to decades. Such predictions are generally performed using GCMs. Unfortunately, as mentioned above, current GCMs have biases that reduce the accuracy of the simulated sea ice in the Southern Ocean. In addition, taking into account observations to initialise these models, generally through simple data assimilation (DA) methods, did not improve the quality of the predictions in the Southern Ocean (Zunz et al., 2013). However, two recent studies performed in a perfect model framework, i.e. using pseudo-observations provided by a reference simulation of the model instead of actual observations, underlined some predictability of the Antarctic sea ice (e.g. Holland et al., 2013; Zunz et al., 2014). According to these studies, at interannual timescales, the predictability is limited to a few years ahead. Besides, significant predictability is found for the trends spanning several decades. Both studies have pointed out that the heat anomalies stored in the interior ocean could play a key role in the predictability of the sea ice. In particular, in their idealised study, Zunz et al. (2014) have described a link between the skill of the prediction of the sea ice cover and the quality of the initialisation of the ocean below it.

On the basis of those results, the present study aims to identify a procedure that could improve the quality of the predictions of the sea ice in the Southern Ocean at multidecadal timescales. Unlike Holland et al. (2013) and Zunz et al. (2014), the results discussed here have been obtained in a realistic framework. It means that actual observations are used to initialise the model simulations as well as to assess the skill of the model. The results of Holland et al. (2013) and Zunz et al. $(2013,2014)$ encouraged us to focus on the prediction of the multi-decadal trends in sea ice concentration or extent rather than on its evolution at interannual timescales. Our study deals with two aspects that could influence the quality of the predicted trend in sea ice in the Southern Ocean: the initial state of the simulation and the magnitude of the freshwater input associated, for instance, with the Antarctic ice sheet mass imbalance. The initialisation procedure is based on the nudging proposal particle filter (NPPF, Dubinkina and Goosse, 2013), a data assimilation method that requires a large ensemble of simulations. Such a large amount of simulations cannot be afforded with GCMs because of their requirements in CPU time. We have thus chosen to work with an Earth-system model of intermediate complexity, LOVECLIM1.3. It has a coarser resolution and a lower level of complexity than a GCM, resulting in a lower computational cost. However, it behaves similarly to the GCMs in the Southern Ocean (Goosse and Zunz, 2014). It thus seems relevant to use this model to study the evolution of the Antarctic sea ice.

The climate model LOVECLIM1.3 is briefly described in Sect. 2.1, along with a summary of the simulations performed in this study. The data assimilation method used to compute the initial conditions of the hindcast simulations is presented in Sect. 2.2. Section 2.3 explains how the additional freshwater flux is taken into account in the simulations. Details about the estimation of the model skill are given in Sect. 2.4. The discussion of the results is divided into two parts: the simulations with data assimilation that provide the initial states (Sect. 3.1) and the hindcast simulations (Sect. 3.2). Finally, Sect. 4 summarises the main results and proposes conclusions. 


\section{Methodology}

\subsection{Model and simulations}

The 3-D Earth-system model of intermediate complexity LOVECLIM1.3 (Goosse et al., 2010) used here includes representations of the atmosphere (ECBilt2, Opsteegh et al., 1998), the ocean and the sea ice (CLIO3, Goosse and Fichefet, 1999) and the vegetation (VECODE, Brovkin et al., 2002). The atmospheric component is a T21 (corresponding to a horizontal resolution of about $5.6^{\circ} \times 5.6^{\circ}$ ), three-level quasi-geostrophic model. The oceanic component consists of an ocean general circulation model coupled to a sea ice model with horizontal resolution of $3^{\circ} \times 3^{\circ}$ and 20 unevenly spaced vertical levels in the ocean. The vegetation component simulates the evolution of trees, grasses and desert, with the same horizontal resolution as ECBilt2. The simulations performed in this study span the period 1850-2009 and are driven by the same natural and anthropogenic forcings (greenhouse gases increase, variations in volcanic activity, solar irradiance, orbital parameters and land use) as the ones adopted in the historical simulations performed in the framework of CMIP5 (Taylor et al., 2011).

Three kinds of simulation are performed in this study and all of them consist of 96-member ensembles. First, a simulation driven by external forcing only provides a reference to measure the predictive skill of the model that can be accounted for by the external forcing alone (NODA in Table 1). This numerical experiment does not take into account any observation, neither in its initialisation nor during the integration. At the initialisation and every 3 months of simulation, the surface air temperature of each members of NODA is slightly perturbed, to have an experimental design as close as possible to the simulations with data assimilation (see below). Second, simulations that assimilate observations of surface air temperature anomalies (see Sect. 2.2 for details) are used to reconstruct the past evolution of the system, from January 1850 to December 2009, and to provide initial conditions for hindcast simulations. Third, the hindcast simulations are initialised on 1 January 1980 from a state extracted from a simulation with data assimilation and are not constrained by the observations during the model integration.

Two simulations with data assimilation, from 1850 to 2009, are analysed here: one without additional freshwater flux (DA_NOFWF in Table 1) and one that is forced by an autoregressive freshwater flux described in Sect. 2.3 (DA_FWF in Table 1), representing crudely the meltwater input to the Southern Ocean. The simulation DA_NOFWF provides the initial state of the first hindcast (HINDCAST_1 in Table 1). The three hindcasts HINDCAST_2.1, HINDCAST_2.2 and HINDCAST_2.3 (see Table 1) are initialised from a state extracted from DA_FWF. These three hindcasts differ amongst each other in the additional freshwater flux they receive during the model integration. No additional freshwater flux is applied for HINDCAST_2.1. HIND-
CAST_2.2 is forced by a time series resulting from the ensemble mean of the additional freshwater flux diagnosed in DA_FWF. The average over the period 1980-2009 of the ensemble mean diagnosed from DA_FWF is applied in HINDCAST_2.3 as a constant additional flux.

\subsection{Data assimilation: the nudging proposal particle filter}

Data assimilation consists of a combination of the model equations and the available observations, in order to provide an estimate of the state of the system as accurate as possible (Talagrand, 1997). The data assimilation simulations performed here provide a reconstruction of the past evolution of the climate system over the period 1850-2009. Such a long period appears necessary because of the long memory of the Southern Ocean. It allows the ocean to be dynamically consistent with the surface variables, constrained by the observations, over a wide depth range. The state of the system on 1 January 1980 is then extracted and used to initialise the hindcast. After the initialisation, the hindcast is driven by external forcing only and no further observations are taken into account.

In this study, observed anomalies of surface air temperature are assimilated in LOVECLIM1.3 thanks to a nudging proposal particle filter (Dubinkina and Goosse, 2013). The assimilated observations are from the HadCRUT3 data set (Brohan et al., 2006). This data set has been derived from in situ land and ocean observations and provides monthly values of surface air temperature anomalies (with regard to 1961-1990) since January 1850. Model anomalies of surface air temperature are computed with regard to a reference computed over 1961-1990 as well, from a simulation driven by the external forcing only, without data assimilation and additional freshwater flux.

The NPPF is based on the particle filter with sequential resampling (e.g. van Leeuwen, 2009; Dubinkina et al., 2011) that consists of three steps. First, an ensemble of simulations, the particles, is integrated forward in time with the model. These particles are initialised from a set of different initial conditions. Therefore, each particle represents a different solution of the model. Second, after 3 months of simulation, a weight is attributed to each particle of the ensemble based on its agreement with the observations. To compute this weight, only anomalies of surface air temperature southward of $30^{\circ} \mathrm{S}$ are taken into account. Third, the particles are resampled: the ones with small weight are eliminated while the ones with large weight are retained and duplicated, in proportion to their weight. This way, a constant number of particles is maintained throughout the procedure. A small perturbation is applied on the duplicated particles to generate different solutions of the model and the three steps are repeated until the end of the period of interest.

In the NPPF, a nudging is applied on each particle during the model integration. It consists of adding to the model 
Table 1. Summary of the simulations analysed in this study.

\begin{tabular}{|c|c|c|c|c|c|}
\hline Simulation & $\begin{array}{l}\text { Number of } \\
\text { members }\end{array}$ & Time period & Initialisation & $\begin{array}{l}\text { Data } \\
\text { assimilation }\end{array}$ & $\begin{array}{l}\text { Additional freshwater flux during the } \\
\text { simulation }\end{array}$ \\
\hline NODA & 96 & Jan 1850-Dec 2009 & on 1 Jan 1850 & NO & NO \\
\hline DA_NOFWF & 96 & Jan 1850-Dec 2009 & on 1 Jan 1850 & YES & NO \\
\hline DA_FWF & 96 & Jan 1850-Dec 2009 & on 1 Jan 1850 & YES & Autoregressive FWF following Eq. (1). \\
\hline HINDCAST_1 & 96 & Jan 1980-Dec 2009 & $\begin{array}{l}\text { on } 1 \text { Jan } 1980 \\
\text { from DA_NOFWF }\end{array}$ & NO & $\mathrm{NO}$ \\
\hline HINDCAST_2.1 & 96 & Jan 1980-Dec 2009 & $\begin{array}{l}\text { on } 1 \text { Jan } 1980 \\
\text { from DA_FWF }\end{array}$ & NO & NO \\
\hline HINDCAST_2.2 & 96 & Jan 1980-Dec 2009 & $\begin{array}{l}\text { on } 1 \text { Jan } 1980 \\
\text { from DA_FWF }\end{array}$ & NO & $\begin{array}{l}\text { Ensemble mean of the FWF computed in } \\
\text { DA_FWF between } 1980 \text { and } 2009 \text { (see Fig. 6). }\end{array}$ \\
\hline HINDCAST_2.3 & 96 & Jan 1980-Dec 2009 & $\begin{array}{l}\text { on } 1 \text { Jan } 1980 \\
\text { from DA_FWF }\end{array}$ & NO & $\begin{array}{l}\text { Ensemble mean of the FWF computed in } \\
\text { DA_FWF, averaged over the period } 1980-2009 \\
(=0.01 \mathrm{~Sv}) \text {. }\end{array}$ \\
\hline
\end{tabular}

equations a term that pulls the solution towards the observations (e.g. Kalnay, 2007). The nudging alone, i.e. not in combination with another DA method, has been used in many recent studies on decadal predictions (e.g. Keenlyside et al., 2008; Pohlmann et al., 2009; Dunstone and Smith, 2010; Smith et al., 2010; Kröger et al., 2012; Swingedouw et al., 2012; Matei et al., 2012; Servonnat et al., 2014). In LOVECLIM1.3, the nudging has been implemented as an additional heat flux between the atmosphere and the ocean $Q=\gamma\left(T_{\mathrm{mod}}-T_{\mathrm{obs}}\right) . T_{\mathrm{mod}}$ and $T_{\mathrm{obs}}$ are the monthly mean surface air temperature simulated by the model and from the observations respectively. $\gamma$ determines the relaxation time and equals $120 \mathrm{~W} \mathrm{~m}^{-2} \mathrm{~K}^{-1}$, a value similar to the ones used in other studies (e.g. Keenlyside et al., 2008; Pohlmann et al., 2009; Smith et al., 2010; Matei et al., 2012; Swingedouw et al., 2012; Servonnat et al., 2014). The nudging is applied on every ocean grid cell, except the ones covered by sea ice and the amplitude of the nudging applied on a particle is taken into account in the computation of its weight (Dubinkina and Goosse, 2013).

\subsection{Autoregressive additional freshwater flux}

As the freshwater related to the melting of the Antarctic ice sheet may contribute to the variability of the sea ice extent (e.g. Hellmer, 2004; Swingedouw et al., 2008; Bintanja et al., 2013), it appears relevant to check its impact on the data assimilation simulations as well as on the hindcasts. However, deriving the distribution of the freshwater flux from the estimate of the observed Antarctic ice sheet mass imbalance is not possible for the whole period covered by our simulations, because of the lack of data. Furthermore, the configuration of the model used in our study does not allow simulating this freshwater flux in an interactive way. We have thus chosen to apply a random freshwater flux, described in term of an autoregressive process as in Mathiot et al. (2013), on each particle during the data assimilation simulations DA_FWF (see Table 1 for details). This allows determining the most adequate value of the additional freshwater flux for the model

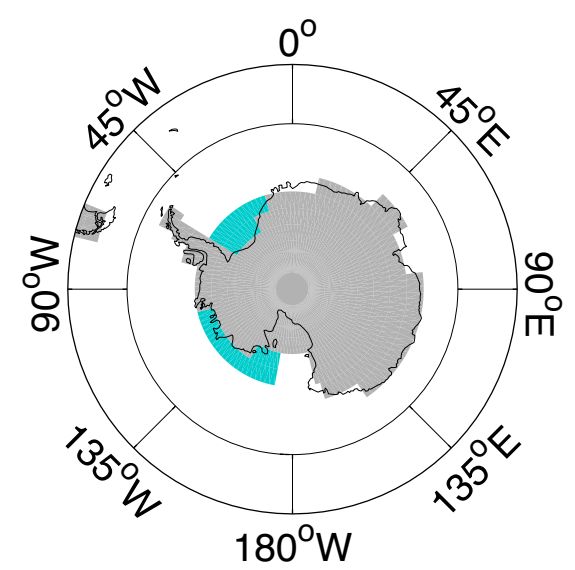

Figure 1. Spatial distribution of the additional freshwater flux included in model simulations (shaded blue). The shaded grey areas correspond to the land mask of the ocean model.

using the NPPF. Because of this additional freshwater flux, the parameters selected to define the error covariance matrix, required to compute the weight of each particle (see Dubinkina et al., 2011), are slightly modified in comparison to the values applied for these parameters in the data assimilation without additional freshwater flux (DA_NOFWF).

The freshwater flux is computed every 3 months, i.e. with the same frequency as the particle filtering. In DA_FWF, the additional freshwater flux is defined as

$\mathrm{FWF}(t)=0.8 \mathrm{FWF}(t-1)+\epsilon_{\mathrm{FWF}}(t)$,

where $\epsilon_{\mathrm{FWF}_{-} 1}$ is a random noise following a Gaussian distribution $N\left(0, \sigma_{\mathrm{FWF}_{-} 1}\right)$, with $\sigma_{\mathrm{FWF}-1}$ equal to $40 \mathrm{mSv}$.

The parameters of the autoregressive processes described in Eq. (1) have been chosen with the goal to obtain a freshwater flux roughly compatible with the estimates of the current Antarctic ice sheet mass loss. The standard deviation of the resulting additional freshwater flux obtained from the simulation DA_FWF (see Fig. 6), computed from the averages over independent 6-year time periods between 1850 and 
2009 , equals $7 \mathrm{mSv}\left(\approx 218 \mathrm{Gt} \mathrm{yr}^{-1}\right)$. This value of the standard deviation is about 3 times larger than the changes in the freshwater input derived from the West Antarctic ice sheet melting between the periods 1992-2000 and 2005-2010 reported in the reconciled estimates of Shepherd et al. (2012) $\left(\approx 64 \mathrm{Gtyr}^{-1}\right)$. Alternatively, we can also consider that the ice sheet mass imbalance is not the only contributor to the additional freshwater flux required by the model. For instance, variations in precipitation are also expected to impact the freshwater balance in the Southern Ocean and might not be simulated adequately by the model. A formulation of the additional freshwater flux that allows stronger variations of this freshwater flux and implies a larger impact has also been tested. The results of this additional simulation are discussed in Sect. S1 of the Supplement, along with three additional hindcast simulations.

The melting of the Antarctic ice sheet being particularly strong over West Antarctica (e.g. Rignot et al., 2008; Velicogna, 2009; Pritchard et al., 2012; Shepherd et al., 2012), we have chosen to distribute uniformly the freshwater flux in the ocean between 0 and $170^{\circ} \mathrm{W}$, south of $70^{\circ} \mathrm{S}$ (area in blue on Fig. 1). Here, the distribution of the freshwater flux is thus not limited to the cells adjacent to Antarctica, unlike Bintanja et al. (2013); Swart and Fyfe (2013). This is based on the assumption that a part of the freshwater might be redistributed offshore by icebergs (e.g. Silva et al., 2006) or coastal currents not well represented in a coarse-resolution model. The spatial distribution of the additional freshwater flux likely impacts the model results. Here, we have chosen a spatial structure as simple as possible, consistent with the available observations, in order to limit the parameters associated with the additional freshwater flux. A detailed investigation of the impact of different spatial distributions of the additional freshwater input on the model solutions would probably provide insightful results but is out of the scope of the present study.

The additional freshwater flux increases the range of solutions reached by the particles and can randomly bring some of them closer to the observations. When a particle is picked up because of its large weight, it is duplicated and the copied particles inherit the value of the freshwater flux that possibly brought the particle close to the observations. This value keeps influencing the copied particles because the freshwater flux is autoregressive. It could thus improve the efficiency of the particle filter. Furthermore, by selecting the solutions that best fit the observations, the particle filter allows estimating the freshwater flux that is more likely to provide a state compatible with the observations.

\subsection{Skill assessment}

In order to measure the skill of the model combined with the assimilation of observations, the results of the data assimilation simulations and of the hindcasts are compared to observations of the annual mean sea ice concentration (the fraction of a grid cell covered by sea ice) and sea ice extent (the sum of the areas of all grid cells having a sea ice concentration above $15 \%$ ), between 1980 and 2009. This corresponds to the period for which reliable observations of the whole ice covered area are available. The sea ice concentration and extent data used here, unless specified otherwise, have been derived from the Nimbus-7 SMMR and DMSP SSM/I-SSMIS satellite observations through version 2 of the Bootstrap algorithm (Comiso, 1999). The impact of the uncertainty of those estimates on our conclusion is discussed in Sects. 3 and 4.

Particular attention is paid to the trend in sea ice concentration and extent. Significance levels for the trends are computed on the basis of a two-tailed $t$-test. The autocorrelation of the residuals is taken into account in both the standard deviation of the trend and in the number of degrees of freedom used to determine the significance threshold (e.g. Santer et al., 2000; Stroeve et al., 2012). This statistical test provides an estimate of the relative significance of the trend, but we have to keep in mind that the assumptions inherent to this kind of test are rarely totally satisfied in the real world (e.g. Santer et al., 2000).

The ensemble means computed for the results of the data assimilation simulations consist of weighted averages. The ensemble mean $X(y, m)$ of the variable $x$, for the month $m$ in the year $y$ is thus defined as

$X(y, m)=\frac{1}{K} \sum_{k=1}^{K} x_{k}(y, m) \cdot w_{k}(y, m)$,

where $k$ is the member index, $K$ is the number of members within the ensemble and $w_{k}(y, m)$ is the weight attributed to the member $k$ during the data assimilation procedure. The ensemble means of each month of the year are then averaged over a year to obtain the annual mean.

The standard deviation of the annual mean of the ensemble cannot be computed explicitly because of the possible time discontinuity in the results of individual members, arising from the resampling occurring every 3 months. An estimate of this standard deviation is however assessed by multiplying the weighted standard deviation of each month of a year by a coefficient and averaging it over the year. These coefficients are introduced to take into account the fact that the standard deviation of the annual mean is not the mean of the standard deviation from every month. They are obtained here by computing the mean ratio between the ensemble standard deviation of the annual mean and the ensemble standard deviation of each month in the simulation NODA.

The ensemble means and standard deviations calculated for NODA and for the hindcast simulations correspond to classical values that do not include any weight as this procedure is only required when data assimilation is applied. 


\section{Results}

In this section, the results of the various simulations (see Table 1 for details) are discussed. First, the reconstructions of the evolution of the sea ice between 1850 and 2009, provided by the simulations NODA, DA_NOFWF and DA_FWF, are presented in Sect. 3.1 and compared to observations. Second, the hindcasts initialised with a state extracted from a data assimilation simulation are analysed to measure the skill of the prediction system tested in this study (Sect. 3.2).

\subsection{Data assimilation simulations}

The observations of yearly mean sea ice extent, based on version 2 of the Bootstrap algorithm, display a positive trend between 1980 and 2009 equal to $19.0 \times 10^{3} \mathrm{~km}^{2} \mathrm{yr}^{-1}$, significant at the $99 \%$ level (Fig. 2). This trend in sea ice extent is the result of an increase in sea ice concentration in most part of the Southern Ocean, particularly in the Ross Sea (Fig. 3a).

When no data assimilation is included in the model simulation (NODA), the ensemble mean displays a decreasing trend in sea ice extent in response to the external forcing (Fig. 2a and b), similar to the one found in other climate models (e.g. Zunz et al., 2013). Consequently, for the ensemble mean, 30-year trends are negative during the whole period of the simulation without data assimilation (Fig. 2b). Over the period 1980-2009, the ensemble mean of the trend in sea ice extent equals $-15.5 \times 10^{3} \mathrm{~km}^{2} \mathrm{yr}^{-1}$, with an ensemble standard deviation of $14.5 \times 10^{3} \mathrm{~km}^{2} \mathrm{yr}^{-1}$, and the reduction of sea ice concentration occurs everywhere in the Southern Ocean (Fig. 3b), except in the Ross Sea and in the Western Pacific sector. This negative trend obtained for the ensemble mean is the result of a wide range of behaviours simulated by the different members belonging to the ensemble (light green shading in Fig. 2a and b) and, considered individually, the members can thus provide positive or negative values for the trend. This indicates thus that, for some members, the natural variability could compensate for the negative trend in sea ice extent simulated in response to the external forcing. Positive trends similar to the one observed over the last 30 years are however rare in NODA. For instance, only 14 of the 96 members have a positive trend over the period 19802009 and none of them have a trend larger than the observed one.

In NODA, the ensemble mean displays an increase in the heat contained in both the upper ocean, defined here as the first $100 \mathrm{~m}$ below the surface, and the interior ocean, considered to lie between -100 and $-500 \mathrm{~m}$ (green solid lines in Fig. 4a and b). The correlation between these two variables equals 0.89 over the period 1980-2009 (Table 2). This warming of the ocean results directly from the increase in the external forcing and is consistent with the decrease in sea ice extent (Fig. 2a). Besides, the ocean salt content in the first $100 \mathrm{~m}$ decreases (Fig. 4c). This is likely due to the enhanced hydrological cycle in a global warming context and the inher- ent increase in precipitation at high southern latitudes that freshens the ocean surface (e.g. Liu and Curry, 2010; Fyfe et al., 2012). Indeed, in NODA, the freshwater input resulting from precipitation integrated south of $60^{\circ} \mathrm{S}$ is about $365 \mathrm{mSv}$ in the early 1850s and increases up to about $375 \mathrm{mSv}$ in 2009. In the simulation NODA, the negative correlation of -0.94 between the ocean heat and salt content in the first $100 \mathrm{~m}$ below the surface over the period 1980-2009 (see Table 2) is linked to the response of these two variables to the external forcing. Nevertheless, this contribution of the external forcing can be masked in individual members by internal variability, leading to low correlations between the heat content at surface and in the interior or between heat and salt contents at surface on average over the ensemble (Table 2).

As the ocean heat content in ice-covered regions is related to the temperature of the freezing point, which is in turn determined by the salinity of the seawater, the co-variations of the ocean heat and salt contents may be constrained by the salinity dependance of the freezing point temperature. Nevertheless, in all our simulations, the variations in the sea surface salinity associated with the freshwater input imply very weak changes in the freezing point temperature (standard deviation $=0.001{ }^{\circ} \mathrm{C}$ over the period $1850-2009$ ). Besides, the variations in the upper ocean heat content in NODA correspond to a standard deviation of the ocean temperature averaged over the first $100 \mathrm{~m}$, south of $60^{\circ} \mathrm{S}$, equal to $0.03^{\circ} \mathrm{C}$. Therefore, it can be reasonably assumed that the salinity dependance of the freezing point temperature has a negligible impact on the ocean temperature and heat content.

If observations of the anomalies of the surface air temperature are assimilated during the simulation, without additional freshwater flux (DA_NOFWF), the model is able to capture the observed interannual and multi-decadal variability of this variable, as expected (Fig. 5b). Consequently, the trend in the ensemble mean sea ice extent is more variable than in NODA. Over the period 1850-2009, the values of the 30 -year trend in sea ice extent, computed from the ensemble mean, stand between $-29.1 \times 10^{3}$ and $13.6 \times 10^{3} \mathrm{~km}^{2} \mathrm{yr}^{-1}$ (Fig. 2d). Between 1980 and 2009, the trend in sea ice extent equals $-3.0 \times 10^{3} \mathrm{~km}^{2} \mathrm{yr}^{-1}$. On average over the ensemble, the trend is thus less negative than in the case where no observations are taken into account during the simulation but it still has a sign opposite to the observed one. The difference with the estimates derived from version 2 of the Bootstrap algorithm between November 1978 and December 2009 is of the order of $20 \times 10^{3} \mathrm{~km}^{2} \mathrm{yr}^{-1}$. The difference with the estimates from version 1 of the Bootstrap algorithm is slightly smaller, being around $15 \times 10^{3} \mathrm{~km}^{2} \mathrm{yr}^{-1}$ (Eisenman et al., 2014). The trends in sea ice concentration display a pattern roughly similar to the observed one (Fig. 3a and c), with an increase in the eastern Weddell Sea, in the eastern Indian sector, in the Western Pacific sector and in the Ross Sea, the sea ice concentration decreasing elsewhere. The decrease in sea ice concentration occurring in the Bellingshausen and Amund- 
(a) NODA - sea ice extent

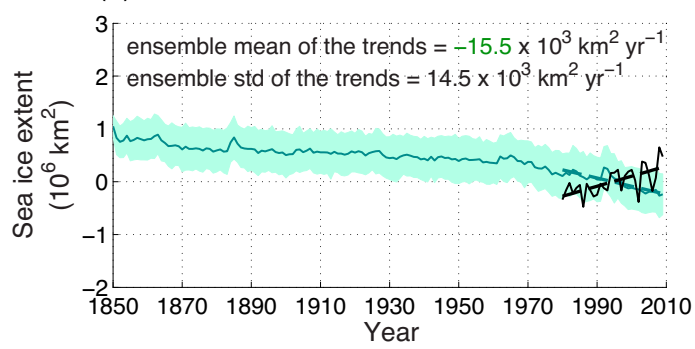

(c) DA_NOFWF- sea ice extent

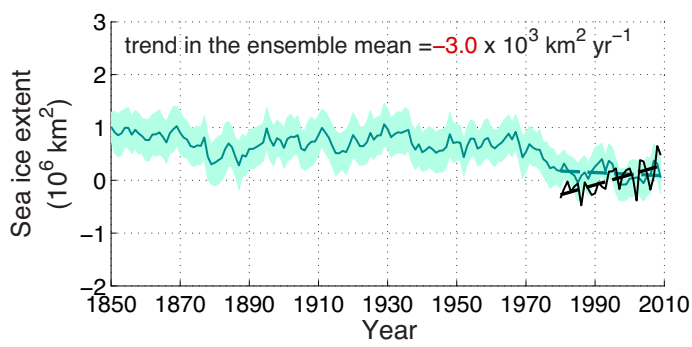

(e) DA_FWF - sea ice extent

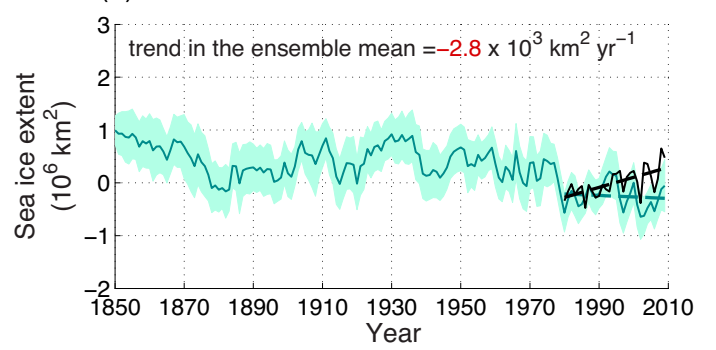

(b) NODA - SIE 30-yr running trend

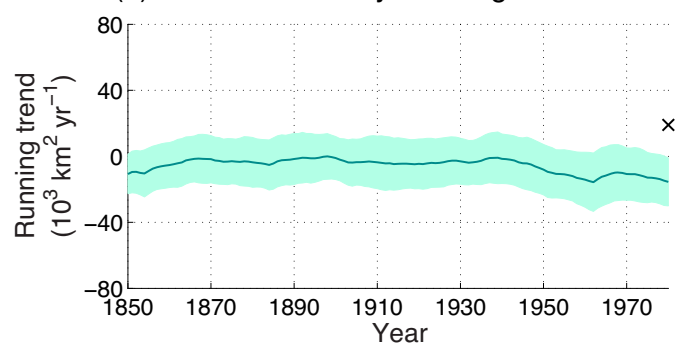

(d) DA_NOFWF - SIE 30-yr running trend

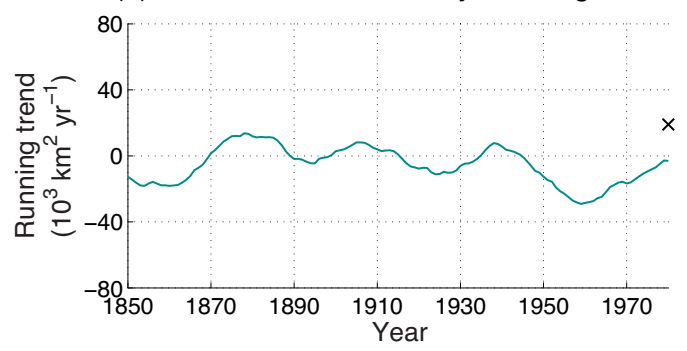

(f) DA_FWF - SIE 30-yr running trend

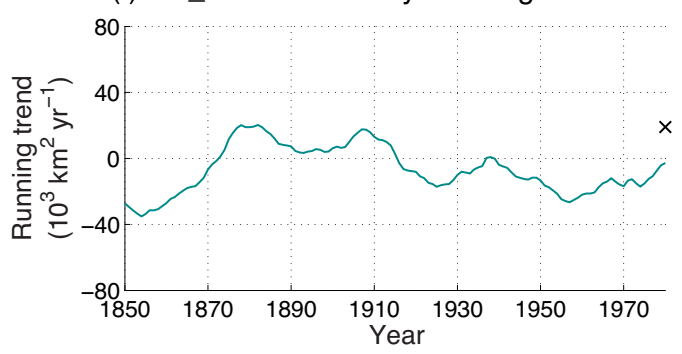

$\begin{array}{ll}\text { Ensemble mean } & \text { Observations } \\ \text { Ensemble mean }+/-1 \text { std } & - \text { Observations linear fit } \\ \text { - } & \text { Model linear fit }\end{array}$

Figure 2. (a, c, e) Yearly mean sea ice extent anomalies with regard to 1980-2009 and (b, d, f) 30-year running trend in sea ice extent. Results are from (a, b) the simulation without data assimilation (NODA), (c, $\mathbf{d})$ the model simulation that assimilates anomalies of surface air temperature (DA_NOFWF) and (e, f) the model simulation that assimilates anomalies of surface air temperature and that is forced by an additional autoregressive freshwater flux following Eq. (1) (DA_FWF). The model ensemble mean is shown as the dark green line surrounded by one standard deviation shown as the light green shading. Observations (Comiso, 1999) are shown as the black line (cross) in (a, c, e) (in b, d, f). The green (black) dashed line shows the linear fit of the model simulation (observations) in (a, $\mathbf{c}$, e). The values of the trend indicated in (a, c, e) correspond to the ensemble mean of the trends, computed over the period 1980-2009, along with the ensemble standard deviation for NODA. Trends that are (non-)significant at the $99 \%$ level are shown in green (red).

sen seas is, however, overestimated by the model, leading to the decrease of the overall extent.

In the simulation DA_NOFWF, the ocean heat content in both the upper and interior ocean is lower than the ones obtained in the simulation NODA until about 1980 (Fig. 4a and $b$ ). This arises from the lower surface air temperature in DA_NOFWF compared to NODA (Fig. 5a and b) that cools down the whole system. The correlation between the upper and interior ocean heat contents equals 0.34 over the period 1980-2009 (Table 2) and is thus lower than for the ensemble mean in NODA. This could be due to the interannual variability captured thanks to the data assimilation that miti- gates the global warming signal (see below). The ocean salt content is larger in DA_NOFWF than in NODA until 1980, likely because of the weakening of the hydrological cycle associated with the lower simulated temperature. Indeed, in DA_NOFWF, the freshwater input associated with precipitation integrated over the area south of $60^{\circ} \mathrm{S}$ equals $363 \mathrm{mSv}$ on average between 1850 and 1980 , against $368 \mathrm{mSv}$ in NODA over the same period. From 1980 onwards, the ocean heat content, in both the upper and middle layer, increases and the salt content decreases in response to the external forcing, as in NODA. Nevertheless, as the ocean heat content is still slightly lower in the simulation DA_NOFWF than in the 
(a) Observations

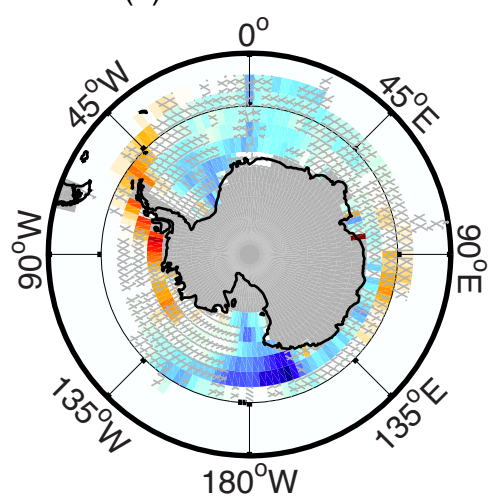

(c) DA_NOFWF

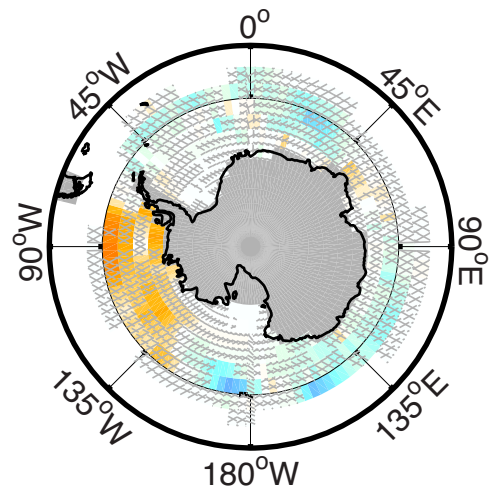

(b) NODA

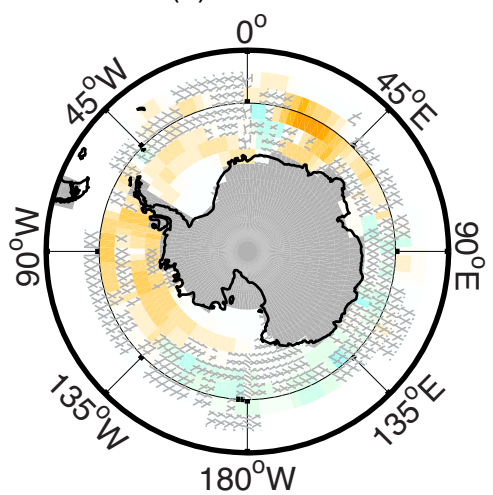

(d) DA_FWF

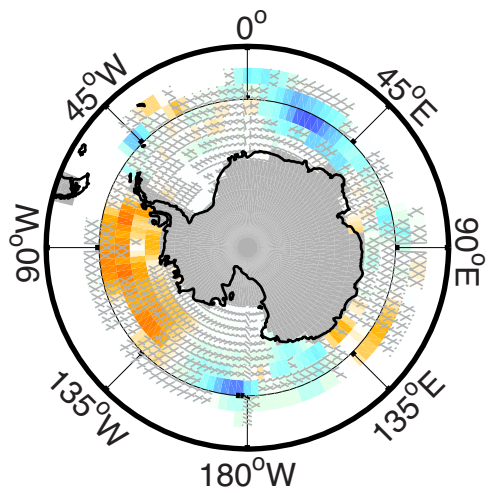

Trend in annual mean sea ice concentration $\left(\mathrm{yr}^{-1}\right)-1980-2009$

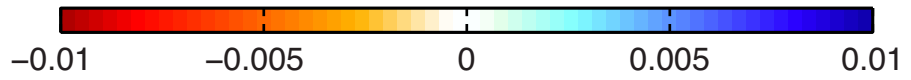

Figure 3. Trend in yearly mean sea ice concentration between 1980 and 2009, shown for (a) the observations (Comiso, 1999), (b) the model simulation without data assimilation (NODA), (c) the model simulation that assimilates anomalies of surface air temperature (DA_NOFWF) and (d) the model simulation that assimilates anomalies of surface air temperature and that is forced by an additional autoregressive freshwater flux following Eq. (1) (DA_FWF). Hatched areas highlight the grid cells where the trend is not significant at the $99 \%$ level. The shaded grey areas correspond to the land mask of the ocean model.

Table 2. Correlation between the ocean heat content in the first $100 \mathrm{~m}$ below the surface and the ocean heat content between -500 and $-100 \mathrm{~m}$ (second column) and correlation between the ocean heat content and the ocean salt content in the first $100 \mathrm{~m}$ below the surface (third column), for the different simulations summarised in Table 1. The correlation is computed over the period 1980 and 2009 , from the ensemble mean of the variables. For the simulation NODA, the correlation computed for each member of the simulation and averaged over the ensemble is given in brackets.

\begin{tabular}{lrr}
\hline Simulation & $\begin{array}{r}\text { Correlation between the upper } \\
\text { and interior ocean heat content }\end{array}$ & $\begin{array}{r}\text { Correlation between the upper } \\
\text { ocean heat and salt contents }\end{array}$ \\
\hline NODA & $0.89(0.03)$ & $-0.94(-0.02)$ \\
DA_NOFWF & 0.34 & -0.28 \\
DA_FWF & -0.24 & 0.35 \\
HINDCAST_1 & 0.86 & -0.94 \\
HINDCAST_2.1 & 0.07 & -0.03 \\
HINDCAST_2.2 & -0.44 & 0.44 \\
HINDCAST_2.3 & -0.32 & 0.27 \\
\hline
\end{tabular}


(a) Ocean heat content between 0 and $-100 \mathrm{~m}$

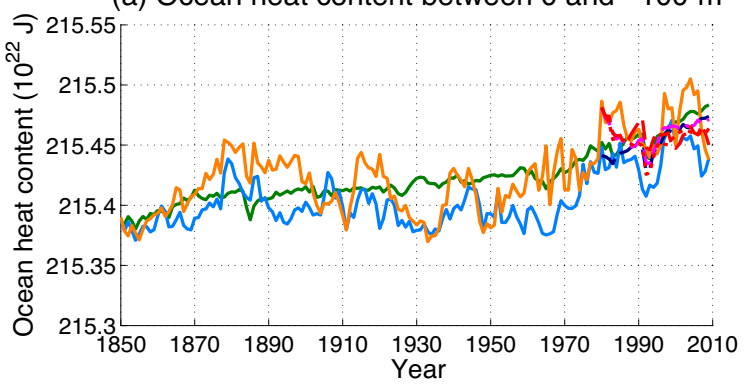

(b) Ocean heat content between -100 and $-500 \mathrm{~m}$

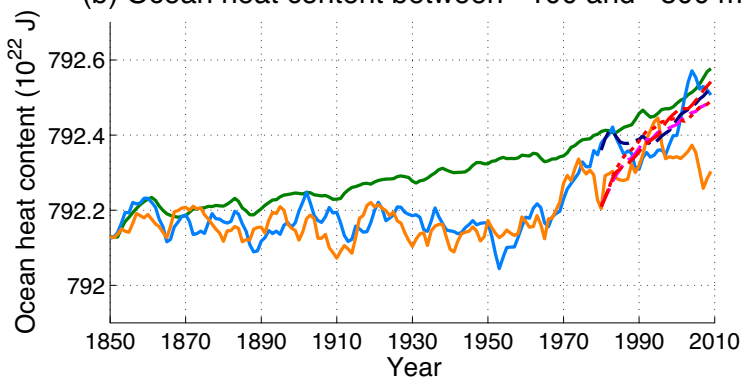

(c) Ocean salt content between 0 and $-100 \mathrm{~m}$

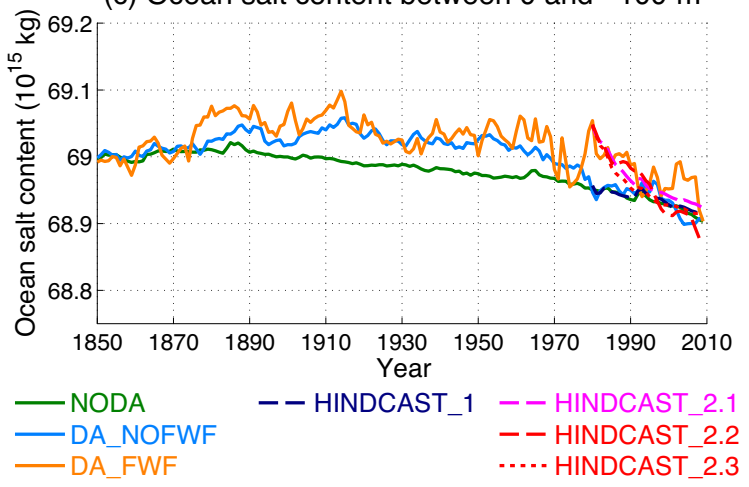

Figure 4. Ensemble mean of yearly mean (a) ocean heat content in the first $100 \mathrm{~m}$ below the surface, (b) ocean heat content between -100 and $-500 \mathrm{~m}$ and (c) ocean salt content in the first $100 \mathrm{~m}$ below the surface, for the simulations summarised in Table 1. The ocean heat and salt contents are computed south of $60^{\circ} \mathrm{S}$. The ocean heat content is computed against absolute zero.

simulation NODA, the quantity of energy available to melt the sea ice at the surface is also lower. This can explain why the absolute value of the trend in sea ice extent between 1980 and 2009 is smaller in DA NOFWF than in NODA.

Including a freshwater flux following the autoregressive process defined in Eq. (1) in the simulation DA_FWF increases the variance of the ensemble of particles. This also slightly enhances the variability of the ensemble mean sea ice extent at interannual and multi-decadal timescales (Fig. 2e, f). Over the period 1850-2009, the values of the 30-year trend in sea ice extent, computed from the ensemble mean, lie between $-35.2 \times 10^{3} \mathrm{~km}^{2} \mathrm{yr}^{-1}$ and $20.3 \times 10^{3} \mathrm{~km}^{2} \mathrm{yr}^{-1}$ (Fig. 2f). Over the period 1980-2009, the trend in sea ice (a) NODA

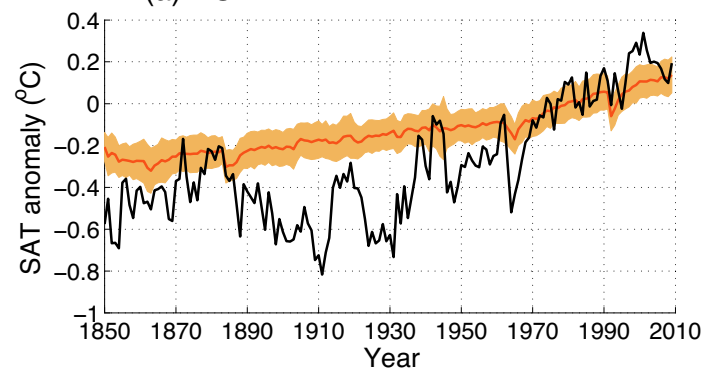

(b) DA_NOFWF

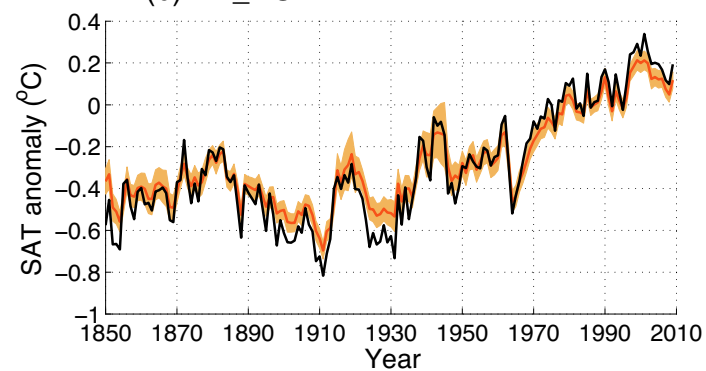

(c) DA_FWF

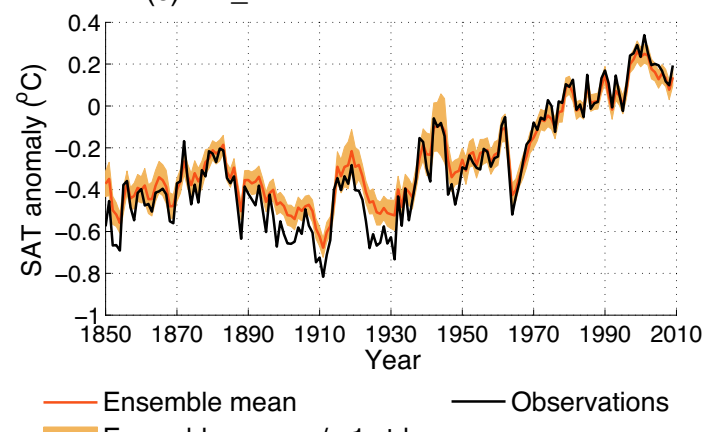

Figure 5. Yearly mean surface air temperature anomalies with regard to 1961-1990, averaged over the area south of $30^{\circ} \mathrm{S}$, from (a) the model simulation without data assimilation (NODA), (b) the model simulation that assimilates anomalies of surface air temperature (DA_NOFWF) and (c) the model simulation that assimilates anomalies of surface air temperature and that is forced by an additional autoregressive freshwater flux following Eq. (1) (DA_FWF). The model ensemble mean is shown as the orange line, surrounded by one standard deviation shown as the light orange shading. Observations (Brohan et al., 2006) are shown as the black line.

extent in DA_FWF equals $-2.8 \times 10^{3} \mathrm{~km}^{2} \mathrm{yr}^{-1}$ and is thus slightly less negative than in the simulation DA_NOFWF. The spatial distribution of the trends in sea ice concentration in DA_FWF is also in good agreement with the observations (Fig. 3d). The decrease in sea ice concentration occurring in the Bellingshausen and Amundsen seas is less widespread than in DA_NOFWF but it is still overestimated. The increase in the eastern Weddell and Ross seas is better represented than in DA_NOFWF as well.

The additional freshwater flux in DA_FWF also induces a higher variability of the heat and salt contents in the up- 


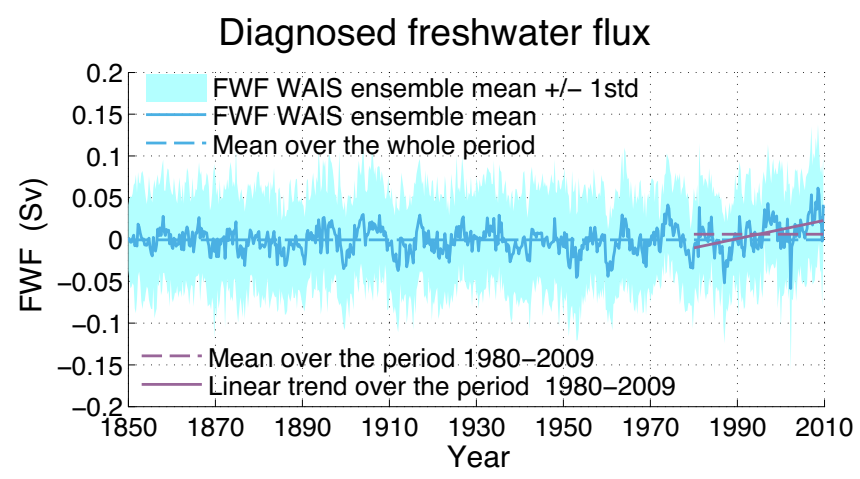

Figure 6. Freshwater flux from the model simulation with data assimilation and additional autoregressive freshwater flux following Eq. (1) (DA_FWF). The ensemble mean is shown as the blue solid line, surrounded by one standard deviation shown as the light blue shading. The dashed blue (purple) line shows the mean over the period 1850-2009 (1980-2009). The linear fit between 1980 and 2009 is shown as the solid purple line.

per ocean compared to the simulation DA_NOFWF (Fig. 4a, c). The correlation between the upper and interior ocean heat contents has a negative value of -0.24 over the period 1980 2009 (see Table 2), which means that when the ocean surface is colder, the intermediate layer is warmer and vice versa. This indicates that, in this experiment, the heat content in the water column is strongly influenced by vertical mixing. The amplitude of this mixing depends on the difference in density between the surface and the deeper layers, which is in turn determined by the difference in temperature and salinity. In the simulation DA_FWF, the correlation between the ocean salt and heat contents in the first $100 \mathrm{~m}$ reaches a value of 0.35 , while it is negative for the ensemble mean in NODA and in DA_NOFWF (see Table 2). This confirms that, during periods of increase in salt content in the upper layer, the vertical mixing in the ocean is enhanced, allowing positive heat anomalies to be transported from the interior to the upper ocean. The heat content in the first $100 \mathrm{~m}$ increases while the one between -100 and $-500 \mathrm{~m}$ decreases. In contrast, when the salt content in the upper layer decreases, the ocean becomes more stratified, preventing the heat exchange between the surface and the interior ocean. The heat is trapped in the interior ocean that gets warmer, and the upper ocean cools down. This process appears more important in DA_FWF than for the individual members of NODA (see Table 2) because of the effect of the additional freshwater flux on the stratification. Keep in mind that correlation between the heat content in the upper and intermediate layers is very high in the ensemble mean of NODA because of the contribution of the forcing.

Because of the additional freshwater flux that tends to stabilise the water column during some periods and to destabilise it in others (Fig. 6), the general behaviour of the ocean in the simulation DA_FWF differs from the simula- tion NODA and DA_NOFWF. While the latter simulations appear mainly driven by the external forcing, the interaction between the different layers in the ocean seems to be dominant in DA_FWF. In the simulation DA_FWF, the ocean heat and salt contents of the surface layer are particularly large in 1980 while the heat content between 100 and $500 \mathrm{~m}$ is low. This implies that the heat storage at depth in 1980 is much lower in DA_FWF than in NODA. Note that the heat content of the top $500 \mathrm{~m}$ in DA_FWF is also lower than in NODA. After 1980, the salt content in DA_FWF decreases until 2009 (Fig. 4c). This is associated with a decrease (increase) in the upper (interior) ocean heat content until the early 1990s, suggesting a reduction of the vertical ocean heat flux. This is likely responsible for the weaker decrease in sea ice extent between 1980 and 2009 in DA_FWF (Fig. 2e). In DA_FWF, the additional freshwater flux is the main cause of the variability of the stratification. Additionally, internal processes can be responsible for such changes in vertical exchanges, as discussed in detail in Goosse and Zunz (2014), also leading to a negative correlation between the heat content in surface and intermediate layers. This explains why the correlation between those two variables is lower for the ensemble mean of DA_NOFWF than in NODA. It is also much lower in individual simulations of NODA ( 0.03 on average, Table 2 ) than in the ensemble mean ( 0.89 , Table 2$)$, the ensemble mean amplifying the contribution of the response to the forcing associated with high positive value.

The additional freshwater flux also weakens the link between the sea ice and the surface air temperature because of the larger role of the changes in oceanic stratification. The correlation between the sea ice and the surface air temperature remains negative in the presence of an additional freshwater flux, i.e. a warmer ocean surface is still associated with a smaller sea ice extent. Nevertheless, the correlation between the ensemble mean of the averaged sea surface temperature and the ensemble mean of the sea ice extent over the period 1850-2009 is smaller in absolute value in the simulation with data assimilation including an additional freshwater flux ( -0.78 in DA_FWF) compared to the simulations without any additional freshwater flux $(-0.97$ in NODA and -0.86 in DA_NOFWF). Keep in mind that the reconstruction of the surface air temperature provided by both DA_NOFWF and DA_FWF is based on the assimilation of surface air temperature data. As expected, the surface air temperature simulated in DA_NOFWF is thus very similar to the one in DA_FWF, both simulations achieving a clear model bias reduction. This bias reduction is, however, obtained differently in the two simulations DA_NOFWF and DA_FWF. For instance, the sea ice simulated in DA_NOFWF, in particular the trend in sea ice extent between 1980 and 2009, differs from the one in DA_FWF. These differences in the simulated sea ice extent are consistent with the modification of the link between the surface air temperature and the sea ice extent induced by the additional freshwater flux. 


\subsection{Hindcast simulations}

In this section, we focus on simulations that are initialised on 1 January 1980 with a state that has been extracted from the data assimilation simulations discussed in Sect. 3.1. After the initialisation, the hindcast simulation is driven by external forcing but no further observations are taken into account. The discussion of analyses here aims at answering two questions. (1) Can the information contained in the initial state persist long enough to impact the simulated trend in sea ice extent? (2) How does an additional freshwater flux impact the sea ice in hindcast simulations? Including an additional freshwater flux appears indeed to be relevant to improve the efficiency of data assimilation (see Sect. 3.1). The results of HINDCAST_1, initialised from DA_NOFWF, and HINDCAST_2.1, initialised from DA_FWF, bring answers to the first question, these hindcasts including no additional freshwater flux. The second question is specifically addressed in the analyses of HINDCAST_2.2 and HINDCAST_2.3, initialised from a state provided by the simulation DA_FWF, a freshwater perturbation being applied during these two hindcasts. Given that it is not clear whether it is the mean value of the additional freshwater flux or its variations that matters, two configurations for the additional freshwater flux have been tested. In HINDCAST_2.2, the additional freshwater flux corresponds to the one that has been diagnosed from DA_FWF, shown on Fig. 6, and evolves in time. In contrast, in HINDCAST_2.3, the freshwater flux is constant in time and equals $0.01 \mathrm{~Sv}$, the average freshwater flux diagnosed in DA_FWF between 1980 and 2009.

In HINDCAST_1, the sea ice extent is high at the beginning of the simulation and decreases between 1980 and 2009 (Fig. 7a). The ensemble mean of the trends equals $-14.2 \times 10^{3} \mathrm{~km}^{2} \mathrm{yr}^{-1}$, with an ensemble standard deviation of $13.2 \times 10^{3} \mathrm{~km}^{2} \mathrm{yr}^{-1}$. This provides a $95 \%$ range that does not encompass the observed trend of $19.0 \times 10^{3} \mathrm{~km}^{2} \mathrm{yr}^{-1}$. In this hindcast, the trend in sea ice concentration is negative over a large area in the Bellingshausen and Amundsen seas and slightly positive elsewhere (Fig. 8b). This pattern thus roughly fits the observed one (Fig. 8a) but the decrease obtained in the western part of the Southern Ocean covers too large an area and the increase in the Weddell and Ross seas is too weak. The regional distribution of the trend in sea ice concentration in HINDCAST_1 (Fig. 8b) is thus very similar to the one in DA_NOFWF, i.e. the simulation that provided the initial state for HINDCAST_1. This suggests that the information provided at the initialisation can slightly impact the solution of the hindcast over multi-decadal timescales. The too large decrease in sea ice concentration occurring in the Bellingshausen and Amundsen seas already noticed in DA_NOFWF is however amplified in HINDCAST_1, leading to an overall decrease in sea ice extent similar to the mean of NODA. The ocean heat and salt contents in HINDCAST_1 follow roughly the evolution of these variables for the ensemble mean in NODA (Fig. 4). The correlation be- tween the upper and interior ocean heat content equals 0.86 and the correlation between the upper ocean heat and salt content equals -0.94 (see Table 2). This points out the role played by the external forcing in this hindcast, as discussed in Sect. 3.1.

In HINDCAST_2.1, the ensemble mean of the trends over the period 1980-2009 equals $1.3 \times 10^{3} \mathrm{~km}^{2} \mathrm{yr}^{-1}$, with an ensemble standard deviation of $14.5 \times 10^{3} \mathrm{~km}^{2} \mathrm{yr}^{-1}$ (Fig. 7b). The observed trend is thus included in the $95 \%$ range of the ensemble. The spatial distribution of the trends in sea ice concentration in HINDCAST_2.1 is also in acceptable agreement with the observations (Fig. 8a, c). Given that no additional freshwater flux is applied in this hindcast, the positive trend in its sea ice extent likely arises from the state used to initialise this simulation. This initial state is characterised by relatively large heat and salt contents in the upper ocean (Fig. 4a, c) and a small heat content in the interior ocean (Fig. 4b). This situation corresponds to a weakly stratified ocean column in 1980 that stabilises during the following years in HINDCAST_2.1, leading to a cooling of the ocean surface that in turn favours the production of sea ice.

HINDCAST_2.2 provides an ensemble mean of the trends over the period 1980-2009 equal to $13.0 \times 10^{3} \mathrm{~km}^{2} \mathrm{yr}^{-1}$, with an ensemble standard deviation of $12.4 \times 10^{3} \mathrm{~km}^{2} \mathrm{yr}^{-1}$ (Fig. 7c). This value of the trend is thus closer to the observation of $19.0 \times 10^{3} \mathrm{~km}^{2} \mathrm{yr}^{-1}$ (corresponding to version 2 of the Bootstrap algorithm) than the one provided by HINDCAST_2.1. Nevertheless, in realistic conditions, this would require obtaining information on the mass balance of the ice sheets spanning the period of the prevision itself. The spatial distribution of the trends in sea ice concentration in HINDCAST_2.2 is very similar to the one in HINDCAST_2.1 (Fig. 8c, d). In HINDCAST_2.3, a constant additional freshwater flux equal to 0.01 , corresponding to the average over the period 1980-2009 of the freshwater flux diagnosed from DA_FWF_1, is applied. This also provides trends in sea ice extent and concentration over the period 1980-2009 that are compatible with the observations (Figs. 7d and 8a, e). For both HINDCAST_2.2 and HINDCAST_2.3, no clear change in the ocean heat and salt contents is noticed compared to HINDCAST_2.1 (Fig. 4). Nevertheless, the additional freshwater flux results in a slightly higher increase in sea ice extent compared to HINDCAST_2.1.

The results of our hindcast simulations demonstrate that the state used to initialise these simulations plays a fundamental role in determining the trends in sea ice extent and concentration over the 3 decades following the initialisation, in agreement with the idealised experiments presented in Zunz et al. (2014). In our simulations, the additional freshwater flux improves the reconstruction of the evolution of the system in the simulation with data assimilation and thus helps to provide an adequate initial state for the hindcasts. An appropriate freshwater input during the last 30 years may further improve the agreement with observations derived from both version 1 and version 2 of the Bootstrap algorithm 
(a) HINDCAST_1

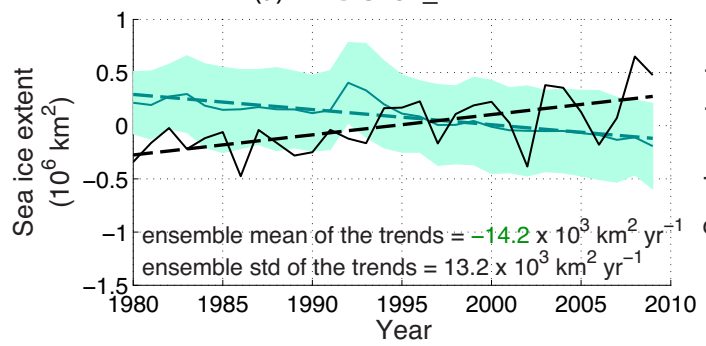

(c) HINDCAST_2.2

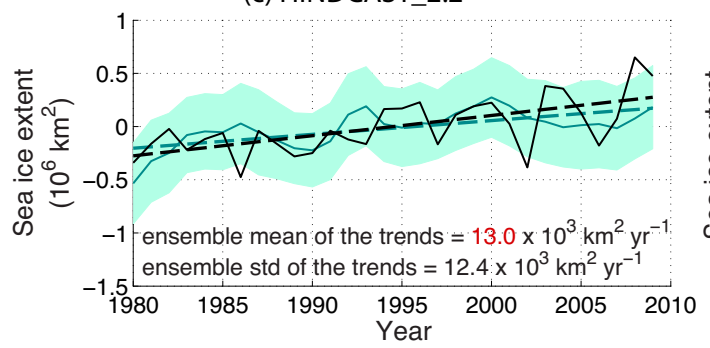

Ensemble mean
Ensemble mean $+/-1$ std
- - Model linear fit

- Observations

- - Observations linear fit

$1980-2009$ trend in the observations $=19.0 \times 10^{3} \mathrm{~km}^{2} \mathrm{yr}^{-1}$ (b) HINDCAST 2.1

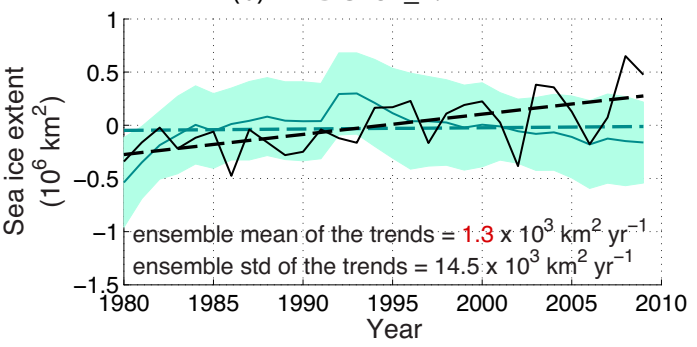

(d) HINDCAST_2.3

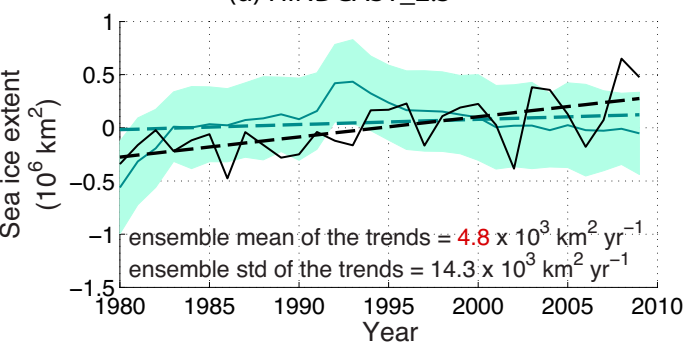

Figure 7. Yearly mean sea ice extent anomalies with regard to 1980-2009, for the four hindcast simulations initialised on 1 January 1980 through data assimilation (see Table 1 for details). The model ensemble mean is shown as the dark green line, surrounded by one standard deviation shown as the light green shading. Observations (Comiso, 1999) are shown as the black line. The green (black) dashed line shows the linear fit of the model simulation (observations). The values of the trend indicated in each panel correspond to the ensemble mean of the trends, computed over the period 1980-2009, along with the ensemble standard deviation. Trends that are (non-)significant at the $99 \%$ level are shown in green (red).

(Eisenman et al., 2014), as shown by the results of HINDCAST_2.2 and HINDCAST_2.3.

As mentioned in Sect. 2.3, another formulation of the additional freshwater flux that allows stronger variations has also been tested. The results of this additional simulation are not discussed in detail here for brevity's sake (for details, see Supplement Sect. S1). In the corresponding simulation with data assimilation, the additional freshwater flux seems to contribute to a reduction of the model biases. Nevertheless, the state associated with such a strongly varying additional freshwater flux is characterised by an enhanced interannual and multi-decadal variability of the sea ice extent as well as the ocean heat and salt contents that may be unrealistic (Figs. S2 and S4). In addition, the strongly varying additional freshwater flux applied during this simulation with data assimilation induces a shift of the system compared to the solution of the model in the absence of any additional freshwater flux. The hindcasts initialised in January 1980 from a state extracted from this simulation provide trends in sea ice extent and concentration, as HINDCAST_2.1, HINDCAST_2.2 and HINDCAST_2.3, that agree relatively well with the observations. Nevertheless, since the initial state used in these hindcasts is shifted, it is essential to apply a constant additional freshwater flux of adequate magnitude during the hindcast simulation in order to ensure the con- sistency of the experimental design and to prevent a drift of the model (for details see Sect. S1).

A change in the freshwater input from one period to the other (for instance between the 30 years preceding and following 1980), in the absence of an adequate initialisation of the simulation, is not sufficient to account for the observed positive trend in sea ice extent between 1980-2009. This conclusion is supported by the results of an additional simulation, initialised in January 1960 from a state extracted from NODA. This simulation is driven by external forcing and receives an additional freshwater input, following the spatial distribution displayed in Fig. 1, equal to $-0.03 \mathrm{~Sv}$ between January 1960 and December 1979 and abruptly increased to $-0.01 \mathrm{~Sv}$ in January 1980, i.e. a larger shift than in any of our simulations with data assimilation or hindcasts. The additional freshwater flux then remains constant until the end of the simulation in December 2009. In this simulation, the sea ice extent decreases between 1960 and 1980 in response to the external radiative forcing and the negative freshwater perturbation (see Sect. S2). The sea ice extent then rapidly increases after the abrupt change in the additional freshwater input in January 1980 but decreases again after a few years, in contrast to observations. 
(a) Observations

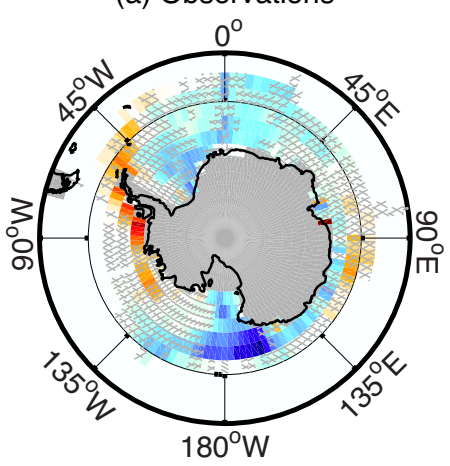

(b) HINDCAST_1

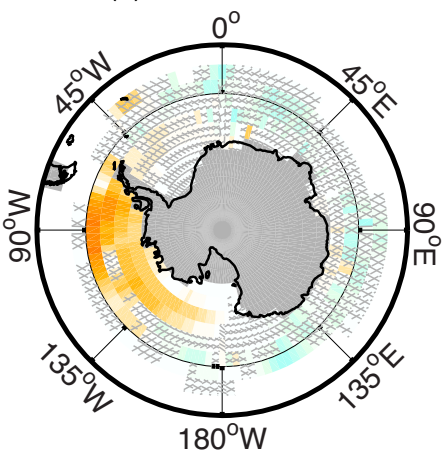

(e) HINDCAST_2.3

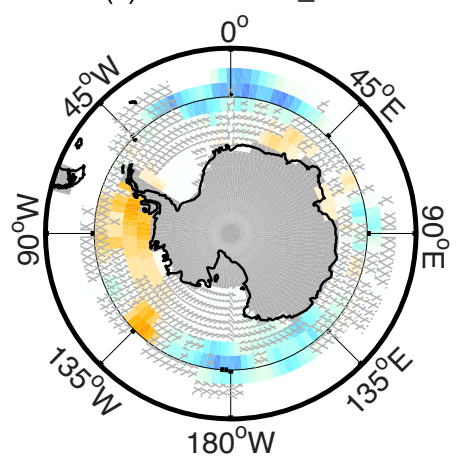

(d) HINDCAST_2.2
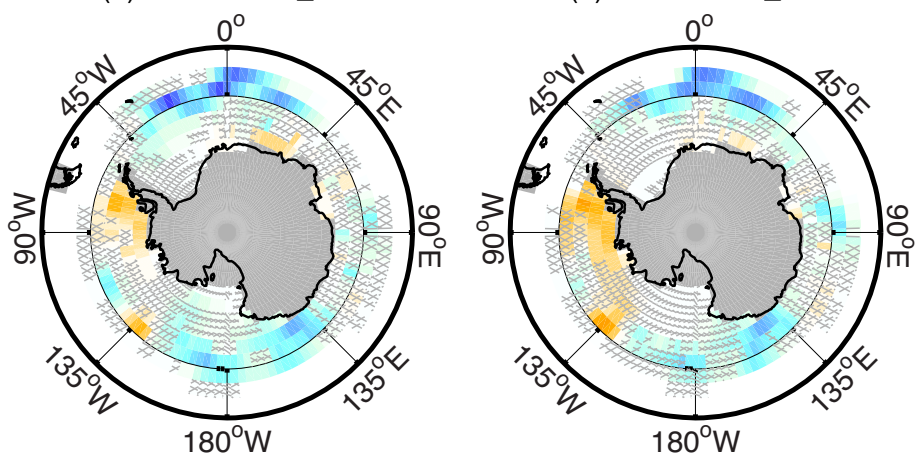

Trend in annual mean sea ice concentration $\left(\mathrm{yr}^{-1}\right)-1980-2009$

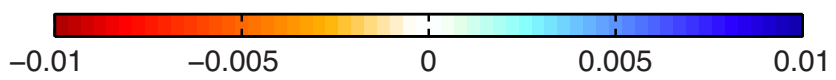

Figure 8. Trend in yearly mean sea ice concentration between 1980 and 2009, for (a) the observations (Comiso, 1999) and (b, c, d, e) the four hindcast simulations initialised on 1 January 1980 through data assimilation (see Table 1 for details). Hatched areas highlight the grid cells where the trend is not significant at the $99 \%$ level. The shaded grey areas correspond to the land mask of the ocean model.

\section{Summary and conclusions}

The trend in sea ice extent derived from satellite observations is subject to uncertainties (e.g. Eisenman et al., 2014) but even the lowest estimate of this trend indicates a slight increase in Antarctic sea ice extent that is not reproduced in our simulation driven by external forcing only. Assimilating anomalies of the surface air temperature through the nudging proposal particle filter induces an increase in the trend in simulated sea ice extent over recent decades in the Southern Ocean, compared to the case where no observation is taken into account. This leads to a better agreement with satellite data than in the simulation without data assimilation. Further improvement is achieved if an additional autoregressive freshwater flux is included during the data assimilation. This freshwater flux induces a larger spread of the ensemble and thus allows a better efficiency of the particle filtering. The additional freshwater input may also compensate for model deficiencies that affect the representation of the freshwater cycle (in particular the variability of the meltwater input), the ocean dynamics, the internal variability, etc. Overall, in combination with the data assimilation, the additional fresh- water input leads to simulated trends in sea ice extent and concentration between 1980 and 2009 that reproduce reasonably well the observations. The freshwater flux thus appears to play an important role on the simulated evolution of the sea ice, as already pointed out in previous studies (e.g. Hellmer, 2004; Swingedouw et al., 2008; Bintanja et al., 2013).

Hindcasts initialised from those simulations with data assimilation identify several factors that can help increase the model skill for predictions of trends in Antarctic sea ice extent and concentration for coming decades. Specifically, we highlight two findings.

1. Initialising a hindcast simulation with a state extracted from a simulation that has assimilated observations through a nudging proposal particle filter has a significant impact on the simulated trends in sea ice extent and concentration over the period 1980-2009. This indicates that the information contained in the initial state influences the results of the simulation over multidecadal timescales, confirming the results of Zunz et al. (2014). As a consequence, an initial condition that adequately represents the observed state is required in order 
to perform skillful predictions for the trend in sea ice extent over the next decades. Nevertheless, the conclusions drawn from our hindcast simulations have to be considered cautiously since they are based on the analyses of the only 30-year period for which we have relevant observations. Similar analyses could be performed for periods starting before 1980, using the reconstruction of the sea ice provided by the simulation with data assimilation as target for the hindcast instead of actual observations. However, this approach would be nearly equivalent to a perfect model study, as proposed in Zunz et al. (2014).

2. In hindcast simulations, the additional freshwater input may help to correctly reproduce the observed positive trend in sea ice extent. Nevertheless, this additional freshwater flux is not the dominant element in our experimental design, in agreement with the results of Swart and Fyfe (2013). Indeed, an abrupt increase in the additional freshwater flux at the beginning of the hindcast simulation, without an adequate initialisation of the simulation, does not provide a long-term increase in sea ice extent such as the one derived from the observations over the last 30 years (Fig. S7).

Our results suggest that the increase in ice extent and the surface cooling between 1980 and 2009 are not due to the greenhouse gas forcing or to a particular large melting of the ice sheet during this period. The evolution of the variables at the surface of the ocean seems rather influenced by the state of the ocean in the 1970s, characterised by a warm and salty surface layer, a cold intermediate layer and strong vertical mixing. This state of the system is consistent with the results of de Lavergne et al. (2014). It then evolves towards a fresher and cooler upper ocean that allows a greater production of sea ice after 1980. In our experiments, this state in the late 1970s is reached thanks to variations in the freshwater input to the Southern Ocean. This flux is very likely playing a role but we could not determine if it is amplified or not by our experimental design that allows variations of this flux only and not of other forcings or model parameters. Overall, the results that have been discussed here are rather encouraging and open perspectives to perform predictions of the sea ice in the Southern Ocean over the next decades.

\section{The Supplement related to this article is available online at doi:10.5194/tc-9-541-2015-supplement.}

Acknowledgements. The authors warmly thank Antoine Barthélemy for his careful reading and helpful comments on the paper. V. Zunz is Research Fellow with the Fonds pour la formation à la Recherche dans l'Industrie et dans l'Agronomie (FRIA-Belgium). H. Goosse is Senior Research Associate with the Fonds National de la Recherche Scientifique (F. R. S. FNRS-Belgium). This work is supported by the Belgian Federal Science Policy (Research Programme on Science for a Sustainable Development). Computational resources have been provided by the supercomputing facilities of the Université catholique de Louvain (CISM/UCL) and the Consortium des Equipements de Calcul Intensif en Fédération Wallonie Bruxelles (CECI) funded by the Fond de la Recherche Scientifique de Belgique (FRS-FNRS).

Edited by: H. Eicken

\section{References}

Bintanja, R., van Oldenborgh, G. J., Drijfhout, S. S., Wouters, B., and Katsman, C. A.: Important role for ocean warming and increased ice-shelf melt in Antarctic sea-ice expansion, Nat. Geosci., 6, 376-379, 2013.

Bitz, C. M. and Polvani, L. M.: Antarctic climate response to stratospheric ozone depletion in a fine resolution ocean climate model, Geophys. Res. Lett., 39, L20705, doi:10.1029/2012GL053393, 2012.

Bitz, C. M., Gent, P. R., Woodgate, R. A., Holland, M. M., and Lindsay, R.: The Influence of Sea Ice on Ocean Heat Uptake in Response to Increasing $\mathrm{CO}_{2}$, J. Climate, 19, 2437-2450, 2006.

Brohan, P., Kennedy, J. J., Harris, I., Tett, S. F. B., and Jones, P. D.: Uncertainty estimates in regional and global observed temperature changes: A new data set from 1850, J. Geophys. Res., 111, D12106, doi:10.1029/2005JD006548, 2006.

Brovkin, V., Bendtsen, J., Claussen, M., Ganopolski, A., Kubatzki, C., Petoukhov, V., and Andreev, A.: Carbon cycle, vegetation, and climate dynamics in the Holocene: Experiments with the CLIMBER-2 model, Global Biogeochem. Cy., 16, 86-1-86-20, doi:10.1029/2001GB001662, 2002.

Comiso, J.: Bootstrap Sea Ice Concentrations from Nimbus-7 SMMR and DMSP SSM/I-SSMIS, Version 2, January 1980 to December 2009, Boulder, Colorado USA: NASA DAAC at the National Snow and Ice Data Center, 1999 (updated daily).

de Lavergne, C., Palter, J. B., Galbraith, E. D., Bernardello, R., and Marinov, I.: Cessation of deep convection in the open Southern Ocean under anthropogenic climate change, Nat. Clim. Change, 4, 278-282, 2014.

Dubinkina, S. and Goosse, H.: An assessment of particle filtering methods and nudging for climate state reconstructions, Clim. Past, 9, 1141-1152, doi:10.5194/cp-9-1141-2013, 2013.

Dubinkina, S., Goosse, H., Sallaz-Damaz, Y., Crespin, E., and Crucifix, M.: Testing a particle filter to reconstruct climate changes over the past centuries, Int. J. Bifurc. Chaos, 21, 3611-3618, doi:10.1142/S0218127411030763, 2011.

Dunstone, N. J. and Smith, D. M.: Impact of atmosphere and subsurface ocean data on decadal climate prediction, Geophys. Res. Lett., 37, L02709, doi:10.1029/2009GL041609, 2010.

Eisenman, I., Meier, W. N., and Norris, J. R.: A spurious jump in the satellite record: has Antarctic sea ice expansion been overestimated?, The Cryosphere, 8, 1289-1296, doi:10.5194/tc-8-12892014, 2014.

Ferreira, D., Marshall, J., Bitz, C. M., Solomon, S., and Plumb, A.: Antarctic Ocean and Sea Ice Response to Ozone Depletion: A Two-Time-Scale Problem, J. Climate, 28, 1206-1226, 2015. 
Fyfe, J. C., Gillett, N. P., and Marshall, G. J.: Human influence on extratropical Southern Hemisphere summer precipitation, Geophys. Res. Lett., 39, L23711, doi:10.1029/2012GL054199, 2012.

Goosse, H. and Fichefet, T.: Importance of ice-ocean interactions for the global ocean circulation: A model study, J. Geophys. Res.-Oceans, 104, 23337-23355, 1999.

Goosse, H. and Zunz, V.: Decadal trends in the Antarctic sea ice extent ultimately controlled by ice-ocean feedback, The Cryosphere, 8, 453-470, doi:10.5194/tc-8-453-2014, 2014.

Goosse, H., Lefebvre, W., de Montety, A., Crespin, E., and Orsi, A.: Consistent past half-century trends in the atmosphere, the sea ice and the ocean at high southern latitudes, Clim. Dynam., 33, 999-1016, 2009.

Goosse, H., Brovkin, V., Fichefet, T., Haarsma, R., Huybrechts, P., Jongma, J., Mouchet, A., Selten, F., Barriat, P.-Y., Campin, J.M., Deleersnijder, E., Driesschaert, E., Goelzer, H., Janssens, I., Loutre, M.-F., Morales Maqueda, M. A., Opsteegh, T., Mathieu, P.-P., Munhoven, G., Pettersson, E. J., Renssen, H., Roche, D. M., Schaeffer, M., Tartinville, B., Timmermann, A., and Weber, S. L.: Description of the Earth system model of intermediate complexity LOVECLIM version 1.2, Geosci. Model Dev., 3, 603-633, doi:10.5194/gmd-3-603-2010, 2010.

Hellmer, H. H.: Impact of Antarctic ice shelf basal melting on sea ice and deep ocean properties, Geophys. Res. Lett., 31, L10307, doi:10.1029/2004GL019506, 2004.

Holland, M. M., Blanchard-Wrigglesworth, E., Kay, J., and Vavrus, S.: Initial-value predictability of Antarctic sea ice in the Community Climate System Model 3, Geophys. Res. Lett., 40, 21212124, doi:10.1002/grl.50410, 2013.

Holland, P. R. and Kwok, R.: Wind-driven trends in Antarctic seaice drift, Nat. Geosci., 5, 872-875, 2012.

Kalnay, E.: Atmospheric Modeling, Data Assimilation and Predictability, Cambridge University Press, Cambridge, 4 Edn., 2007

Keenlyside, N., Latif, M., Jungclaus, J. H., Kornbueh, L., and Roeckner, E.: Advancing decadal-scale climate prediction in the North Atlantic sector, Nature, 453, 84-88, doi:10.1038/nature06921, 2008.

Kirkman, C. H. and Bitz, C. M.: The Effect of the Sea Ice Freshwater Flux on Southern Ocean Temperatures in CCSM3: DeepOcean Warming and Delayed Surface Warming, J. Climate, 24, 2224-2237, 2010.

Kröger, J., Müller, W., and von Storch, J.-S.: Impact of different ocean reanalyses on decadal climate prediction, Clim. Dynam., 39, 795-810, 2012.

Landrum, L., Holland, M. M., Schneider, D. P., and Hunke, E.: Antarctic Sea Ice Climatology, Variability, and Late TwentiethCentury Change in CCSM4, J. Climate, 25, 4817-4838, 2012.

Lefebvre, W. and Goosse, H.: An analysis of the atmospheric processes driving the large-scale winter sea ice variability in the Southern Ocean, J. Geophys. Res., 113, C02004, doi:10.1029/2006JC004032, 2008.

Liu, J. and Curry, J. A.: Accelerated warming of the Southern Ocean and its impacts on the hydrological cycle and sea ice, P. Natl. Acad. Sci., 107, 14987-14992, 2010.

Mahlstein, I., Gent, P. R., and Solomon, S.: Historical Antarctic mean sea ice area, sea ice trends, and winds in CMIP5 simulations, J. Geophys. Res.-Atmos., 118, 1-6, doi:10.1002/jgrd.50443, 2013.
Matei, D., Pohlmann, H., Jungclaus, J., Müller, W., Haak, H., and Marotzke, J.: Two Tales of Initializing Decadal Climate Prediction Experiments with the ECHAM5/MPI-OM Model, J. Climate, 25, 8502-8523, 2012.

Mathiot, P., Goosse, H., Crosta, X., Stenni, B., Braida, M., Renssen, H., Van Meerbeeck, C. J., Masson-Delmotte, V., Mairesse, A., and Dubinkina, S.: Using data assimilation to investigate the causes of Southern Hemisphere high latitude cooling from 10 to 8 ka BP, Clim. Past, 9, 887-901, doi:10.5194/cp-9-887-2013, 2013.

Opsteegh, J. D., Haarsma, R., Selten, F., and Kattenberg, A.: ECBILT: a dynamic alternative to mixed boundary conditions in ocean models, Tellus A, 50, 348-367, 1998.

Pohlmann, H., Jungclaus, J. H., Köhl, A., Stammer, D., and Marotzke, J.: Initializing Decadal Climate Predictions with the GECCO Oceanic Synthesis: Effects on the North Atlantic, J. Climate, 22, 3926-3938, 2009.

Polvani, L. M. and Smith, K. L.: Can natural variability explain observed Antarctic sea ice trends? New modeling evidence from CMIP5, Geophys. Res. Lett., 40, 3195-3199, 2013.

Pritchard, H. D., Ligtenberg, S. R. M., Fricker, H. A., Vaughan, D. G., van den Broeke, M. R., and Padman, L.: Antarctic icesheet loss driven by basal melting of ice shelves, Nature, 484, 502-505, 2012.

Rignot, E., Bamber, J. L., van den Broeke, M. R., Davis, C., Li, Y., van de Berg, W. J., and van Meijgaard, E.: Recent Antarctic ice mass loss from radar interferometry and regional climate modelling, Nat. Geosci., 1, 106-110, 2008.

Santer, B. D., Wigley, T. M. L., Boyle, J. S., Gaffen, D. J., Hnilo, J. J., Nychka, D., Parker, D. E., and Taylor, K. E.: Statistical significance of trends and trend differences in layer-average atmospheric temperature time series, J. Geophys. Res., 105, 73377356, doi:10.1029/1999JD901105, 2000.

Servonnat, J., Mignot, J., Guilyardi, E., Swingedouw, D., Séférian, R., and Labetoulle, S.: Reconstructing the subsurface ocean decadal variability using surface nudging in a perfect model framework, Clim. Dynam., 44, 315-338, doi:10.1007/s00382014-2184-7, 2014.

Shepherd, A., Ivins, E. R., A, G., Barletta, V. R., Bentley, M. J., Bettadpur, S., Briggs, K. H., Bromwich, D. H., Forsberg, R., Galin, N., Horwath, M., Jacobs, S., Joughin, I., King, M. A., Lenaerts, J. T. M., Li, J., Ligtenberg, S. R. M., Luckman, A., Luthcke, S. B., McMillan, M., Meister, R., Milne, G., Mouginot, J., Muir, A., Nicolas, J. P., Paden, J., Payne, A. J., Pritchard, H., Rignot, E., Rott, H., Sørensen, L. S., Scambos, T. A., Scheuchl, B., Schrama, E. J. O., Smith, B., Sundal, A. V., van Angelen, J. H., van de Berg, W. J., van den Broeke, M. R., Vaughan, D. G., Velicogna, I., Wahr, J., Whitehouse, P. L., Wingham, D. J., Yi, D., Young, D., and Zwally, H. J.: A Reconciled Estimate of Ice-Sheet Mass Balance, Science, 338, 1183-1189, doi:10.1126/science.1228102, 2012.

Sigmond, M. and Fyfe, J. C.: Has the ozone hole contributed to increased Antarctic sea ice extent?, Geophys. Res. Lett., 37, L18502, doi:10.1029/2010GL044301, 2010.

Sigmond, M. and Fyfe, J. C.: The Antarctic Sea Ice Response to the Ozone Hole in Climate Models, J. Climate, 27, 1336-1342, doi:10.1175/JCLI-D-13-00590.1, 2013. 
Silva, T. A. M., Bigg, G. R., and Nicholls, K. W.: Contribution of giant icebergs to the Southern Ocean freshwater flux, J. Geophys. Res.-Oceans, 111, C03004, doi:10.1029/2004JC002843, 2006.

Smith, D. M., Eade, R., Dunstone, N. J., Fereday, D., Murphy, J. M., Pohlmann, H., and Scaife, A. A.: Skilful multi-year predictions of Atlantic hurricane frequency, Nat. Geosci., 3, 846-849, doi:10.1038/NGEO1004, 2010.

Smith, K. L., Polvani, L. M., and Marsh, D. R.: Mitigation of 21st century Antarctic sea ice loss by stratospheric ozone recovery, Geophys. Res. Lett., 39, L20701, doi:10.1029/2012GL053325, 2012.

Solomon, S.: Stratospheric ozone depletion: A review of concepts and history, Rev. Geophys., 37, 275-316, 1999.

Stammerjohn, S. E., Martinson, D. G., Smith, R. C., Yuan, X., and Rind, D.: Trends in Antarctic annual sea ice retreat and advance and their relation to El Niño Southern Oscillation and Southern Annular Mode variability, J. Geophys. Res., 113, C03S90, doi:10.1029/2007JC004269, 2008.

Stroeve, J. C., Kattsov, V., Barrett, A., Serreze, M., Pavlova, T., Holland, M., and Meier, W. N.: Trends in Arctic sea ice extent from CMIP5, CMIP3 and observations, Geophys. Res. Lett., 39, L16502, doi:10.1029/2012GL052676, 2012.

Swart, N. C. and Fyfe, J. C.: The influence of recent Antarctic ice sheet retreat on simulated sea ice area trends, Geophys. Res. Lett., 40, 4328-4332, 2013.

Swingedouw, D., Fichefet, T., Huybrechts, P., Goosse, H., Driesschaert, E., and Loutre, M.-F.: Antarctic ice-sheet melting provides negative feedbacks on future climate warming, Geophys. Res. Lett., 35, L17705, doi:10.1029/2008GL034410, 2008.

Swingedouw, D., Mignot, J., Labetoulle, S., Guilyardi, E., and Madec, G.: Initialisation and predictability of the AMOC over the last 50 years in a climate model, Clim. Dynam., 40, 23812399, doi:10.1007/s00382-012-1516-8, 2012.

Talagrand, O.: Assimilation of Observations, an Introduction, J. Meteorol. Soc. Jpn. Ser. II, 75, 191-209, 1997.

Taylor, K. E., Stouffer, R. J., and Meehl, G. A.: An Overview of CMIP5 and the Experiment Design, B. Am. Meteorol. Soc., 93, 485-498, 2011.
Turner, J. and Overland, J.: Contrasting climate change in the two polar regions, Polar Res., 28, 146-164, doi:10.1111/j.17518369.2009.00128.x, 2009.

Turner, J., Bracegirdle, T. J., Phillips, T., Marshall, G. J., and Hosking, J. S.: An Initial Assessment of Antarctic Sea Ice Extent in the CMIP5 Models, J. Climate, 26, 1473-1484, doi:10.1175/JCLID-12-00068.1, 2013.

van Leeuwen, P. J.: Particle Filtering in Geophysical Systems, Mon. Weather Rev., 137, 4089-4114, doi:10.1175/2009MWR2835.1, 2009.

Vaughan, D. G., Comiso, J. C., Allison, I., Carrasco, J., Kwok, R., Mote, P., Murray, T., Paul, F., Ren, J., Rignot, E., Solomina, O., Steffen, K., and Zhang, T.: Observations: Cryosphere, in: Climate Change 2013: The Physical Science Basis. Contribution of Working Group I to the Fifth Assessment Report of the Intergovernmental Panel on Climate Change, edited by: Stocker, T. F., Qin, D., Plattner, G.-K., Tignor, M., Allen, S. K., Boschung, J., Nauels, A., Xia, Y., Bex, V., and Midgley, P. M., Cambridge University Press, Cambridge, United Kingdom and New York, NY, USA, 2013.

Velicogna, I.: Increasing rates of ice mass loss from the Greenland and Antarctic ice sheets revealed by GRACE, Geophys. Res. Lett., 36, L19503, doi:10.1029/2009GL040222, 2009.

Zhang, J.: Increasing Antarctic Sea Ice under Warming Atmospheric and Oceanic Conditions, J. Climate, 20, 2515-2529, 2007.

Zunz, V., Goosse, H., and Massonnet, F.: How does internal variability influence the ability of CMIP5 models to reproduce the recent trend in Southern Ocean sea ice extent?, The Cryosphere, 7, 451-468, doi:10.5194/tc-7-451-2013, 2013.

Zunz, V., Goosse, H., and Dubinkina, S.: Impact of the initialisation on the predictability of the Southern Ocean sea ice at interannual to multi-decadal timescales, Clim. Dynam., 1-20, doi:10.1007/s00382-014-2344-9, 2014. 